\title{
Acute coronary syndrome in congenitally corrected transposition of the great arteries
}

\author{
Konstantinos M Lampropoulos, ${ }^{1}$ Dimitrios Kotsas, ${ }^{1}$ Themistoklis A lliopoulos ${ }^{2}$
}

${ }^{1}$ Department of Cardiology, Polyclinic General Hospital of Athens, Greece 2Department of Cardiology, 251 General Air Force Hospital, Athens, Greece

\section{Correspondence to}

Dr Konstantinos M

Lampropoulos,

konlampropoulos@yahoo.gr
To cite: Lampropoulos KM Kotsas D, lliopoulos T A. BMJ Case Rep Published online: [please include Day Month Year] doi:10.1136/ bcr-2012-008354

\section{DESCRIPTION}

The congenitally corrected transposition of the great arteries (TGA) is a rare condition accounting for less than $1 \%$ of all congenital heart diseases, usually combined with other congenital heart anomalies such as a ventricular septal defect or pulmonary outflow tract obstruction. Very often they present with abnormalities of the left-sided systemic tricuspid valve. In rare cases $(<5 \%)$, some patients have no associated cardiac abnormalities and they can go unnoticed until adulthood. ${ }^{1}$ A 53 -year-old man presented to the emergency department complaining of chest pain suggestive of angina. Medical history was positive for hypercholesterolaemia, smoking and arterial hypertension. The patient also revealed a positive family history of coronary heart disease. The admission ECG showed repolarisation abnormalities of the anterolateral wall (inverted $\mathrm{T}$ waves at leads I, aVL, V1-V5) consistent with ischaemia and suggestive of a possible non-ST elevation myocardial infarction (figure 1). The blood pressure on admission was $150 / 85 \mathrm{~mm} \mathrm{Hg}$ and the patient was haemodynamically stable. The primary differential diagnosis at the time of admission was coronary ischaemia. A bedside transthoracic echocardiogram was performed and the aorta and the pulmonary artery were shown to be transposed. The left and right ventricles were also transposed. Systolic function of both ventricles was normal and the ejection fraction of the right (functionally left) ventricle was estimated to be approximately $60 \%$. There were no identifiable regional wall motion abnormalities of either the left or right ventricle. It needs to be emphasised that a number of limitations hamper the evaluation of the right ventricle by transthoracic echocardiography. However, imaging was performed by an experienced consultant, and the quantitative methods for the evaluation of the right ventricle including tricuspid annular plane systolic excursion and systolic tissue Doppler imaging velocity of the tricuspid annulus were also commensurate with normal function.

Following the early stabilisation phase, cardiac troponin I, creatine kinase and creatine kinase MB mass tests were found marginally positive (troponin levels at $0.28 \mathrm{mg} / \mathrm{dl}$ with a laboratory cut-off value of $0.10 \mathrm{mg} / \mathrm{dl}$ and minor increases of creatine kinase and creatine kinase-MB). The patient was prescribed standard acute coronary syndrome medical treatment as this was the most likely explanation for his clinical condition, including acetylsalicylic acid, clopidogrel, metoprolol, atorvastatin and enalapril. Low molecular weight heparin was also administered. He was promptly referred to the catheterisation laboratory for a coronary angiography and aortography that showed anomalous origin of the coronary arteries with the left coronary artery originating from the right sinus of Valsalva and the right coronary artery originating from the left sinus of Valsalva, a finding typical of congenitally corrected TGA where each coronary artery follows the course of its respective ventricle.

Both coronaries were free of haemodynamically significant stenoses (figure 2A). In light of the angiography result, the cardiac enzyme increase was attributed to microvascular ischaemia possibly because of microvascular atherosclerosis or hypertrophy. A few days later, the patient had a CT angiography and MRI that confirmed the congenitally corrected TGA and the ventricles of the heart and reassessed the systemic (right) and the right (left) ventricular systolic function to be at a level of $60 \%$. The left coronary artery was again shown to originate from the right anterolateral wall of the aorta and the right coronary from the posterolateral wall between the left atrium and the right ventricle (figure 2B-D). Both techniques are useful noninvasive methods for the precise and prompt evaluation of detailed heart anatomy. MRI in particular is now considered to be the gold standard for the assessment of ventricular function and volumes, myocardial wall thickness and the presence and patterns of myocardial scar and fibrosis, especially when delayed gadolinium hyper-enhancement imaging is performed. It can also provide adjunctive information and detect ischaemia with wall motion or myocardial perfusion analysis. ${ }^{1}$

The patient's condition improved markedly within the next few days and there were no signs of heart failure (New York Heart Association Class I). No primary coronary intervention was required and he was discharged on atorvastatin, enalapril and low-dose acetyl salicylic acid as the patient had no indication for repair of the congenitally corrected transposition of the great arteries at that time. The ECG did not change during hospitalisation.

He was referred to a specialised congenital heart disease outpatient department for follow-up and further evaluation. The timing of possible intervention for patients with asymptomatic or only mildly symptomatic congenitally corrected TGA but without associated cardiac lesions remains an area of debate. The classical surgical approach to congenitally corrected TGA has been to repair the associated lesions without addressing the atrioventricular and ventriculoarterial discordance that is a primary feature of the anomaly. In this approach, the morphologically right ventricle remains as the systemic ventricle and the morphologically right atrioventricular valve (tricuspid) remains as the systemic valve. ${ }^{2}$ Ultimately, this often results in tricuspid valve regurgitation, dysfunction of the right 
$10 \mathrm{~mm} / \mathrm{mV} \quad 25 \mathrm{~mm} / \mathrm{s}$ Average
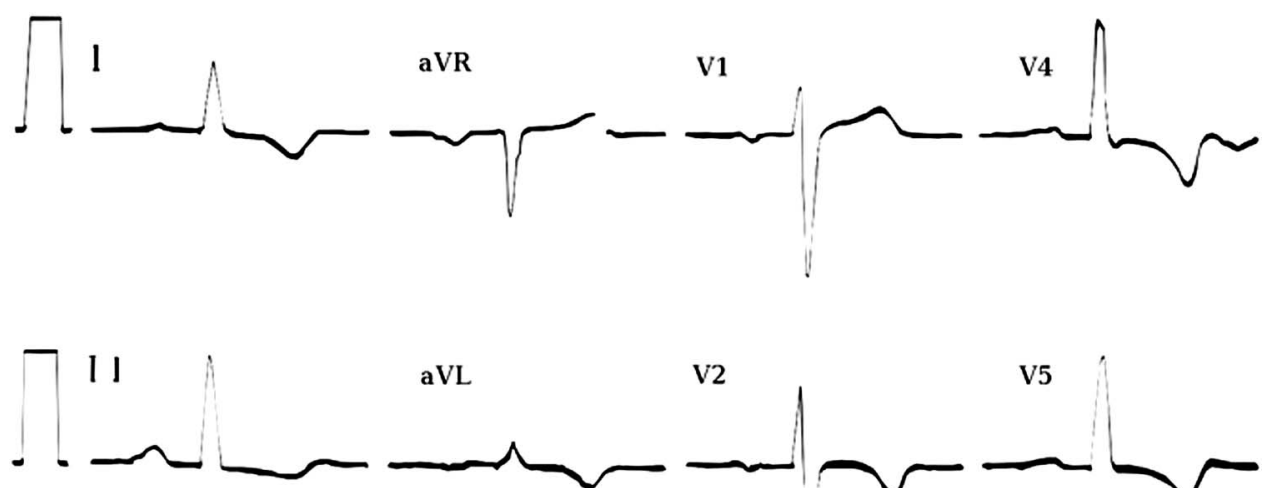<smiles>Ic1ccccc1</smiles>

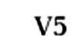

5
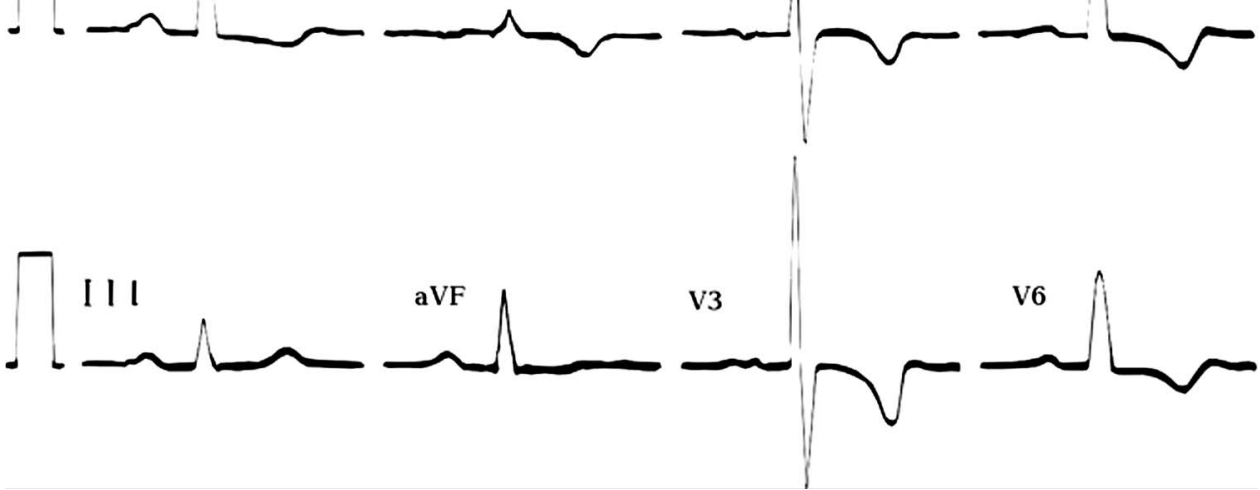

Figure 1 ECG on admission suggestive of ischaemia.

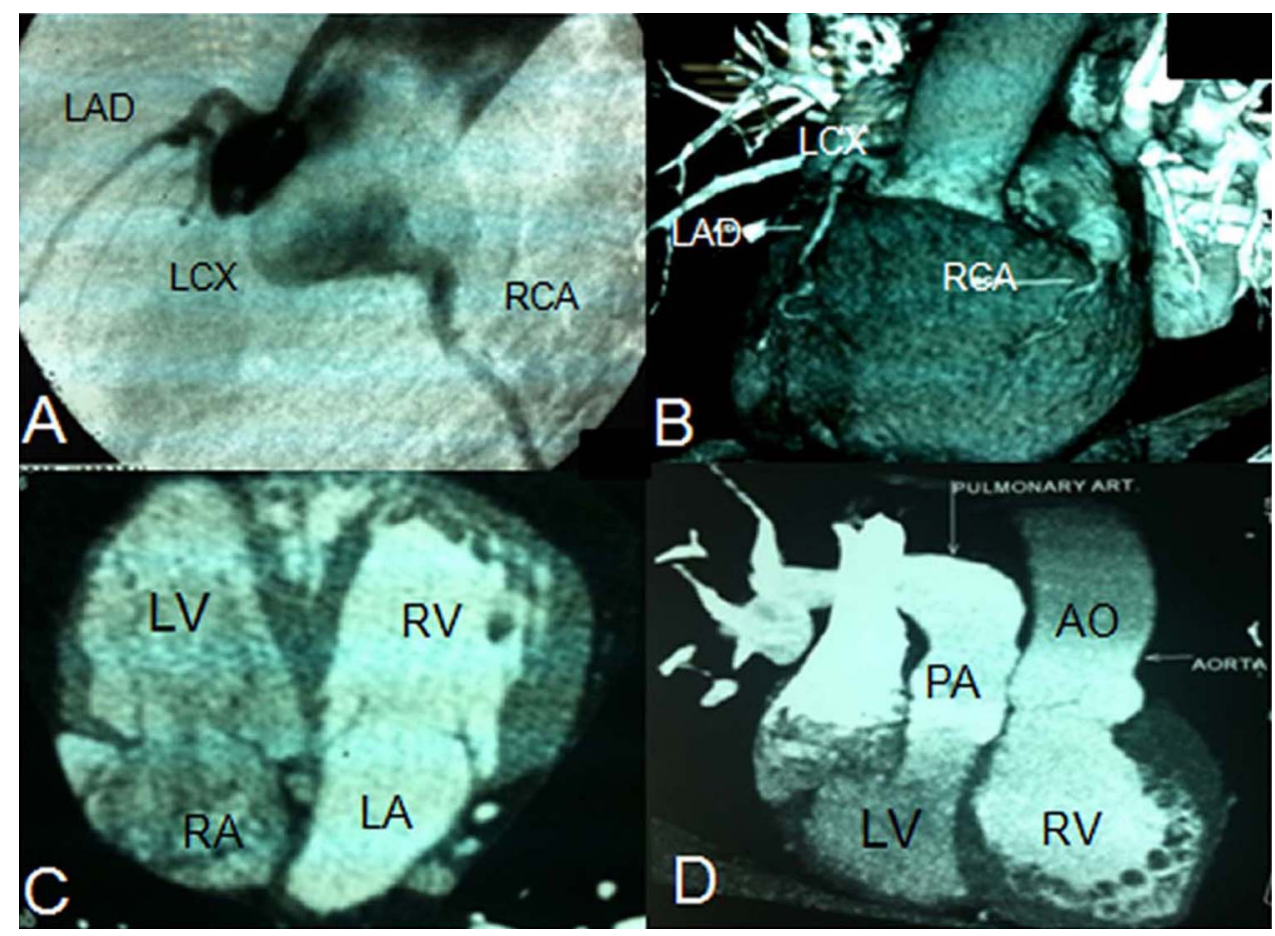

Figure 2 (A) Aortography demonstrated anomalous origin of the coronary arteries with the left coronary originating from the right sinus of Valsalva and the right coronary artery originating from the left sinus of Valsalva. Both coronaries were disease free. (B) CT angiography demonstrated anomalous origin of the coronary arteries with the left coronary originating from the right sinus of Valsalva and the right coronary artery originating from the left sinus of Valsalva. Both coronaries were disease free. (C) MRI shows congenitally corrected transposition of the great arteries and the ventricles of the heart. Atrioventricular and ventriculoarterial discordance is displayed. (D) MRls of congenitally corrected transposition of the great arteries and the ventricles of the heart. Double atrioventricular and ventriculoarterial discordance is evident. 


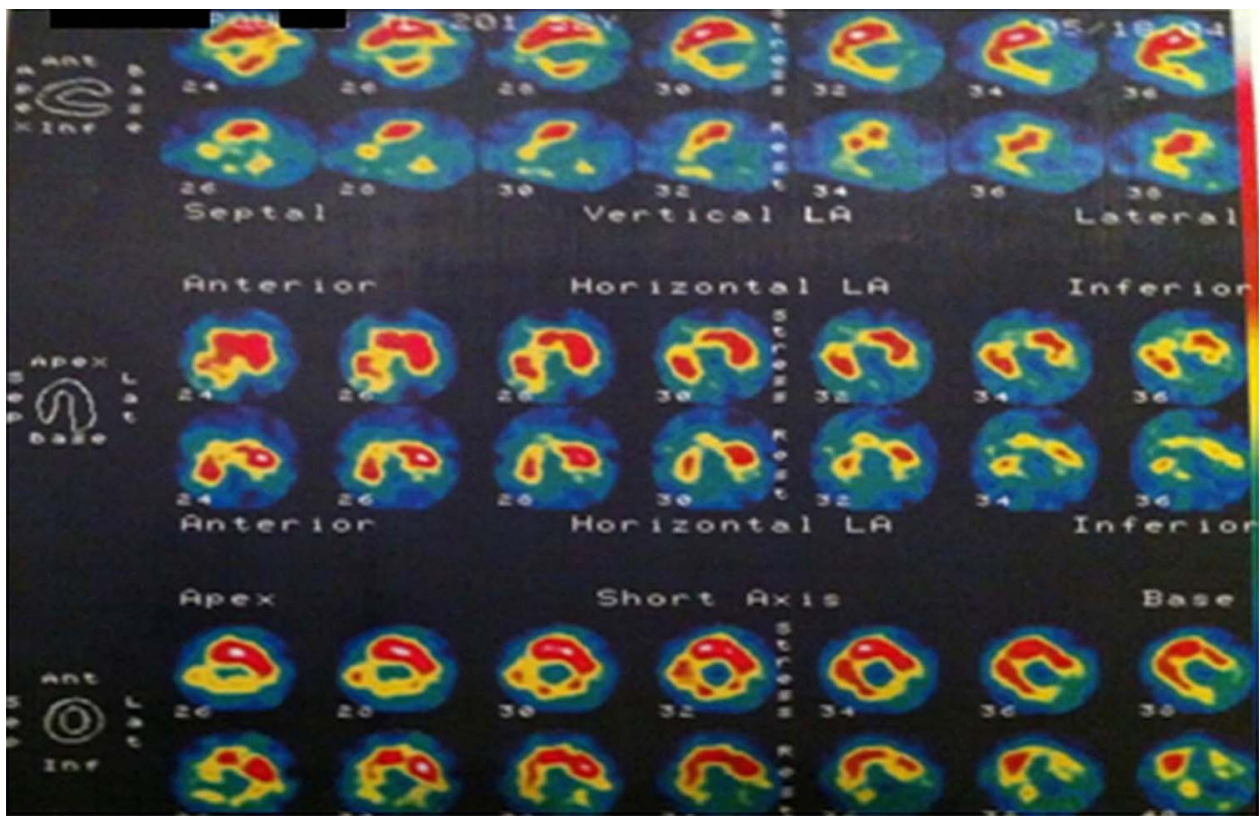

Figure 3 Thallium scintigram revealed both at rest and on exertion increased radiotracer uptake for the right (functionally left) ventricle, probably owing to its compensatory hypertrophy. There was no reversible perfusion defect suggestive of myocardial ischaemia.

ventricle and eventually heart failure. In trying to improve this suboptimal outcome, the double-switch operation was introduced where the left ventricle is incorporated as systemic ventricle and the right ventricle and tricuspid valve are no longer part of the systemic circulation. This approach is often referred to as being an anatomic repair. ${ }^{3}$ It is important to be noted that the rare patient with isolated congenitally corrected TGA is at increased and cumulative over time risk of developing conduction abnormalities. Periodic Holter rhythm monitoring is warranted as often a permanent pacemaker will need to be placed at some stage.

Two months later, the patient was readmitted for recurrent chest pain. He was haemodynamically stable (blood pressure $145 / 85 \mathrm{~mm} \mathrm{Hg}$ ), and his cardiac enzymes and troponin were negative. In light of the pertinent medical history, clinical syndrome and pre-existing ECG abnormalities, a thallium scintigram was arranged for the assessment of possible new myocardial ischaemia, as the coronary anatomy was already known due to the recent angiography. The scintigram revealed increased radiotracer uptake for the right (functionally left) ventricle both at rest and on exertion, probably owing to its compensatory hypertrophy and increased trabeculation. There was no reversible perfusion defect suggestive of myocardial ischaemia (figure 3). Radioisotopic ventriculography (a reproducible technique that provides useful heart chambers' functional information and precisely evaluates wall motion and ejection fraction) was indicative of satisfactory systolic motion of both ventricles at rest and exertion. The ejection fraction for the systemic (right) and for left (right) ventricle was calculated at $60 \%$. A new MRI was not deemed appropriate as recent images were available and the cost effectiveness of a further MRI scan was questionable.

It needs to be emphasised that interventional cardiologists should be aware of the coronary artery anatomy changes and angiography in cases of congenitally corrected TGA performed with vigilance for the possibility of significant abnormalities that could complicate the procedure. Such abnormalities, when present, may affect open heart surgery with unexpected anatomy being associated with higher morbidity and mortality rates. $^{4}$ This serves as a reminder of the essential need for optimal heart anatomy visualisation before planning for repair, ${ }^{5}$ with the use of new heart imaging techniques including CT and MRI. However, transthoracic echocardiography remains the optimal non-invasive, easily accessible, low cost, reproducible and radiation-free method that can effectively visualise the heart chambers.

\section{Learning points}

Congenitally corrected transposition of the great arteries (TGA) is a rare condition accounting for less than $1 \%$ of all congenital heart diseases, usually combined with other congenital heart anomalies. Rarely some patients remain undiagnosed until adulthood and usually have no associated anomalies. It needs to be emphasised that interventional cardiologists should be aware of the coronary artery anatomy changes and angiography in cases of congenitally corrected TGA performed with vigilance for the possibility of significant abnormalities that could complicate the procedure. Such abnormalities, when present, may affect open heart surgery with unexpected anatomy being associated with higher morbidity and mortality rates. ${ }^{4}$

Competing interests None.

Patient consent Obtained.

Provenance and peer review Not commissioned; externally peer reviewed.

\section{REFERENCES}

1 Baumgartner $\mathrm{H}$, Bonhoeffer $\mathrm{P}$, De Groot NM, et al. Task Force on the Management of Grown-up Congenital Heart Disease of the European Society of Cardiology (ESC); Association for European Paediatric Cardiology (AEPC); ESC Committee for Practice Guidelines (CPG). ESC guidelines for the management of grown-up congenital heart disease (new version 2010). Eur Heart J 2010;31:2915-7. 


\section{Images in...}

2 Reddy VM, McElhinney DB, Silverman NH, et al. The double switch procedure for anatomical repair of congenitally corrected transposition of the great arteries in infants and children. Eur Heart J 1997:18:1470-7.

3 Bogers AJ, Head SJ, De Jong PL, et al. Long term follow up after surgery in congenitally corrected transposition of the great arteries with a right ventricle in the systemic circulation. J Cardiothorac Surg 2010;5:74.
4 Piran S, Veldtman G, Siu S, et al. Heart failure and ventricular dysfunction in patients with single or systemic right ventricles. Circulation 2002;105:1189-94.

5 Alghamdi AA, McCrindle BW, Van Arsdell GS. Physiologic versus anatomic repair of congenitally corrected transposition of the great arteries: meta-analysis of individual patient data. Ann Thorac Surg 2006;81:1529-35.

Copyright 2013 BMJ Publishing Group. All rights reserved. For permission to reuse any of this content visit http://group.bmj.com/group/rights-licensing/permissions.

BMJ Case Report Fellows may re-use this article for personal use and teaching without any further permission.

Become a Fellow of BMJ Case Reports today and you can:

- Submit as many cases as you like

- Enjoy fast sympathetic peer review and rapid publication of accepted articles

- Access all the published articles

- Re-use any of the published material for personal use and teaching without further permission

For information on Institutional Fellowships contact consortiasales@bmigroup.com

Visit casereports.bmj.com for more articles like this and to become a Fellow 